\title{
Photophysical and photochemical properties of manganese complexes with cationic porphyrin ligands: effects of alkyl substituents and micellar environment ${ }^{\dagger}$
}

\author{
Melinda A. Fodor ${ }^{\mathrm{a}}$, Ottó Horváth ${ }^{\mathrm{a} *}$, Lajos Fodor ${ }^{\mathrm{a}}$, Katarina Vazdar ${ }^{\mathrm{b}}$, \\ Günter Grampp ${ }^{c}$, Alexander Wankmüller ${ }^{c}$ \\ ${ }^{a}$ Department of General and Inorganic Chemistry, Institute of Chemistry, University of \\ Pannonia, P.O.Box 158, 8201 Veszprém, Hungary \\ ${ }^{\mathrm{b}}$ Division of Physical Chemistry, Ruđer Bošković Institute, P.O.B. 180, HR-10002 Zagreb, \\ Croatia \\ 'Institute of Physical and Theoretical Chemistry, Graz University of Technology, 8010 Graz, \\ Stremayrgasse 9. Austria
}

\begin{abstract}
Although Mn(III) porphyrins were considered earlier to be very weakly emissive, the fluorescence displayed by $\mathrm{Mn}(\mathrm{III})$ complexes with the cationic TMPyP ${ }^{2+}$ ligand $\left(\mathrm{H}_{2} \mathrm{TMPyP}^{4+}\right.$ $=5,10,15,20$-tetrakis (1-methylpyridinium-4-yl)porphyrin) as well as with its other alkyl (such as hexyl and dodecyl) derivatives proved to be strong enough for a comparative study. Elongation of the alkyl substituent increased both the quantum yield and the lifetime of the emission for the $\mathrm{Mn}$ (III) porphyrins, while resulted in an opposite effect for the corresponding free bases in homogeneous solutions. The presence of cationic micelles, however, reversed this tendency regarding the emission lifetime of the complexes. These cationic metalloporphyrins were applied in a photocatalytic system involving triethanolamine (TEOA) as a sacrificial electron donor and methylviologen $\left(\mathrm{MV}^{2+}\right)$ as an acceptor. In the first step of the catalytic process outer-sphere photoinduced reduction of the metal center took place via quenching of the triplet excited state of these metalloporphyrins by TEOA. The corresponding manganese(II) porphyrins formed in this way were also photoactive; they forwarded an electron to $\mathrm{MV}^{2+}$ upon irradiation, regenerating the starting complex. Elongation of the alkyl substituents increased the quantum yield of the formation of methylviologen radical $\left(\mathrm{MV}^{\bullet+}\right)$ in this system, but considerably decreased the durability of the photocatalyst. Anionic micelles totally hindered the photoinduced generation of $\mathrm{Mn}(\mathrm{II})$ porphyrins, while cationic micellar environment appreciably increased the efficiency of the accumulation of $\mathrm{MV}^{\bullet+}$.
\end{abstract}

Keywords: cationic manganese(III) porphyrins; amphiphilic; micellar; fluorescence; photocatalysis; triplet state

\footnotetext{
${ }^{+}$Dedicated to the memory of Professor Ivan Habuš.

* Corresponding author. Tel.: +36 (88) 624000/6049; fax: +36 (88) 624548 (O. Horváth).

E-mail addresses: otto@mk.uni-pannon.hu (O. Horváth), amfor89@ gmail.com (M.A. Fodor), lajos@vegic.uni-pannon.hu (L. Fodor), katarina.vazdar@irb.hr (K. Vazdar), grampp@tugraz.at (G. Grampp), a.wankmueller@tugraz.at (A. Wankmüller).
} 


\section{Introduction}

Metalloporphyrins represent a very important group of compounds playing key roles in nature, due to their special spectral, coordination and redox features. Their favorable photoinduced properties can also be utilized in various photocatalytic procedures [1]. Watersoluble derivatives can be applied in environmentally benign aqueous systems. Kinetically inert in-plane metalloporphyrins, in which the metal center is coplanarly located in the cavity of the ligand, may offer promising possibilities for realization of photocatalytic systems based on outer-sphere electron transfer [2]. Within the normal or in-plane metalloporphyrins, the socalled hyper porphyrins are especially interesting from this viewpoint, due to their distorted structure, which may increase the (photo)redox reactivity of these complexes. The Mn(III) ion of $58 \mathrm{pm}$ ionic radius [3] is rather small compared to the size of the cavity in the ligand center. Thus, it promotes the contraction of the porphyrin ring, distorting it, forming typical hyper porphyrin complexes. According to the generally accepted concept, earlier the highly distorted complexes with $\mathrm{Mn}$ (III) or $\mathrm{Co}$ (III) metal center were considered not to display appreciable fluorescence at room temperature [4]. However, in recent studies characteristic emission spectra were observed in the case of Co(III)TMPyP ${ }^{5+}$ [5] and manganese(III) complexes with 5-[4-(5-carboxy-1-butoxy)-phenyl-10,15,20-tris(1-methylpyridinium-4yl)porphyrin [6], 5,10,15,20-tetraphenylporphyrin, and 5,10,15,20-tetra(3hydroxyphenyl)porphyrin [7].

Photoredox reactions of water-soluble manganese(III) porphyrins, sometimes along with the corresponding cobalt(III) complexes, were investigated in several respects. Photocatalytic oxidation of sulfide to sulfate in a wastewater was studied with Co(III)TMPyP ${ }^{5+}$, $\mathrm{Mn}(\mathrm{III}) \mathrm{TMPyP}^{5+}$, and Fe(III)TMPyP ${ }^{5+}\left(\mathrm{H}_{2} \mathrm{TMPyP}^{4+}=5,10,15,20\right.$-tetrakis(1methylpyridinium-4-yl)porphyrin) [8]. Manganese(III) porphyrins, both cationic $\mathrm{Mn}(\mathrm{III}) \mathrm{TMPyP}^{5+}$ and anionic Mn(III)TSPP ${ }^{3-},\left(\mathrm{H}_{2} \mathrm{TSPP}^{4-}=5,10,15,20\right.$-tetrakis(4sulfonatophenyl)porphyrin), were applied for photocatalytic oxygenation of various bicyclic organic compounds, utilizing visible light $[9,10,11]$. Mn(III)TMPy $\mathrm{P}^{5+}$ proved to be successful also in photoinduced oxidation of polynucleotides [12]. Cationic manganese(III) porphyrins were efficient photocatalysts in the systems containing suitable electron donors (such as EDTA and TEOA) and methylviologen $\left(\mathrm{MV}^{2+}\right.$ ) as an appropriate electron acceptor $[1,13,14]$. However, the mechanism of the catalytic processes has not been completely elucidated. Thus, the aim of our work was to study the photophysical (especially fluorescence) and photochemical (mostly photocatalytic) properties of $\mathrm{Mn}$ (III)TMPyP ${ }^{5+}$ as well as its corresponding hexyl and dodecyl derivative, in order to investigate the effect of the length of alkyl chain. Besides, connecting to the hydrophobic/hydrophilic interactions, the influence of the micellar environment on the photoinduced behaviors was also studied.

\section{Experimental}

\subsection{Materials}

The compounds used in our experiments were of reagent grade. Amphiphilic porphyrin ligands $\left(\mathrm{H}_{2} \mathrm{THPyP}^{4+}=5,10,15,20\right.$-tetrakis(1-hexylpyridinium-4-yl)porphyrin and $\mathrm{H}_{2} \mathrm{TDPyP}^{4+}$ $=5,10,15,20$-tetrakis (1-dodecylpyridinium-4-yl)porphyrin ) were synthesized according to a literature method [15]. $\mathrm{H}_{2} \mathrm{TMPyP}^{4+}$ was purchased from Sigma-Aldrich. For preparation of the manganese(III) porphyrins and for the photoinduced experiments with them, water purified in a Millipore/Milli-Q system was applied as solvent. Stock solutions of manganese(III) porphyrins were prepared by in situ generation by the reaction between the corresponding free base and manganese(II) sulfate (in 4 folds excess at the porphyrin 
concentration of $3 \times 10^{-4} \mathrm{M}$ ) under aerated conditions. The reaction is rather slow at room temperature (at least one week), thus it was accelerated by addition of $\mathrm{HgCl}_{2}$ in a very low concentration $\left(10^{-6} \mathrm{M}\right)$. Catalytic effect of mercury(II) with a large ionic radius (102 pm [3]) is based on the formation of an out-of-plane intermediate $\mathrm{Hg}$ (II)-porphyrin [16]. The distortion of this species makes two diagonal pyrrolic nitrogens more accessible to another metal ion, even with smaller ionic radius, on the other side of the porphyrin ligand [17]. The behavior of the final product (manganese(III) porphyrin) was not affected by the presence of $\mathrm{Hg}(\mathrm{II})$ in the samples prepared by 50-100 times dilution from the stock solution. Control experiments were carried out with commercially available pure $\mathrm{Mn}$ (III)TMPyP ${ }^{5+}$ (from Frontier Scientific), and no deviation was observed from the behavior of the corresponding home-made metalloporphyrin. Borate buffer was applied to adjust $\mathrm{pH}$ to 8.3. In the case of dodecyl substituted porphyrin, the solvent was 1:1 ethanol: water mixture.

\subsection{Analytical procedures}

The absorption spectra were recorded by using a Specord S-600 diode array spectrophotometer. For the measurement of fluorescence a Fluoromax-4 (Horiba JobinYvon) spectrofluorimeter was applied. It was supplemented with a time-correlated single-photon counting accessory for determination of fluorescence lifetimes too. $\mathrm{Ru}(\mathrm{bpy})_{3} \mathrm{Cl}_{2}$ [18] was used as a reference for determination of the fluorescence quantum yields. The emission quantum yield of this complex is 0.042 at $20-25^{\circ} \mathrm{C}$. It displays a strong absorption in the $400-480-\mathrm{nm}$ range, covering the Soret-bands of the free-base porphyrins and their manganese(III) complexes. Considering the relatively long emission lifetime of $\mathrm{Ru}(\mathrm{bpy}) 3^{2+}$, its solution was carefully argon-saturated by 40-min bubbling. Transient absorption measurements were carried out on a laser kinetic equipment described elsewhere [19]. All analytical measurements were realized at room temperature.

\subsection{Photolyses}

Photochemical experiments were carried out with $3.5-\mathrm{cm}^{3}$ argon-saturated solutions in $1-\mathrm{cm}$ cells at room temperature. During the irradiations the reaction mixtures were continuously homogenized by magnetic stirring. For illumination a LED light of 430-490-nm emission with a 457-nm maximum intensity was utilized. Incident light intensity was determined by ferrioxalate actinometry [20,21].The experimental results were processed and evaluated by MS Excel programs on PCs.

\section{Results and Discussion}

\subsection{Photophysical properties}

\subsubsection{Absorption spectra}

Absorption spectra of porphyrins, both free bases and metalloporphyrins, display two types of bands. The Q-bands, assigned to the $\mathrm{S}_{0} \rightarrow \mathrm{S}_{1}$ transitions, can be found in the longerwavelength range (500-700-nm), while the more intense Soret- or B-bands with one order of magnitude higher molar absorbances, assigned to the $S_{0} \rightarrow S_{2}$ transitions, appear in the shorterwavelength range (380-480-nm). Generally, the Soret-bands of the normal (in-plane) metalloporphyrins display characteristic blue-shift compared to that of the corresponding free base, while the out-of-plane (OOP) complexes, in which the metal center, due to its large size, is located above the plane of the porphyrin ligand, distorting it, display red-shifted bands [22, $23,24,25]$. Deviating from the general tendency, however, in the case of the in-plane 
porphyrin complexes of $\mathrm{Mn}(\mathrm{III})$, this band is red-shifted [1, 6, 7]. This phenomenon is well demonstrated by the spectra of $\mathrm{H}_{2} \mathrm{THXPyP}^{4+}$, Mn(III)THXPyP ${ }^{5+}$ and Mn(II)THXPyP ${ }^{5+}$ as shown in Fig 1 and by the data of Table 1. A similar behavior can be observed for the Qbands. In the free-base porphyrins the presence of protons on two (diagonally situated) pyrrolic nitrogens results in a split of the $S_{1}$-state. Hence, the shift of Q-bands must be calculated with respect to the average energy of the $\mathrm{Q}_{\mathrm{x}}(0,0)$ and $\mathrm{Q}_{\mathrm{y}}(0,0)$ bands of the free-base porphyrin.

Such metalloporphyrins, the spectra of which could not be interpreted by the 4 MO theory of Gouterman, have been classified as hyper porphyrins $[25,26]$. In the case of the d-type hyper porphyrins, the metal centers with $\mathrm{d}^{1}$ through $\mathrm{d}^{6}$ configuration have vacancies in the $e_{g}\left(d_{\pi}\right)$ orbitals, which make a porphyrin ligand-to-metal charge transfer transition possible [27]. There is also a mixing of the metal $d_{\pi}$ orbitals with the LUMO of the porphyrin $\left(e_{g}\left(\pi^{*}\right)\right)$ because they are of the same symmetry $\left(e_{g}\right)$ [28]. This extensive mixing easily occurs if the metal orbitals are close in energy to the porphyrin LUMO as in the case of $\mathrm{Mn}(\mathrm{III})$, resulting in a complex spectrum [29]. Nevertheless, a structural distortion may also contribute to this effect; the radius of the low-spin $\mathrm{Mn}^{3+}$ ion is so small (58 pm) that the porphyrin ring contracts, resulting in a ruffled distortion [25].
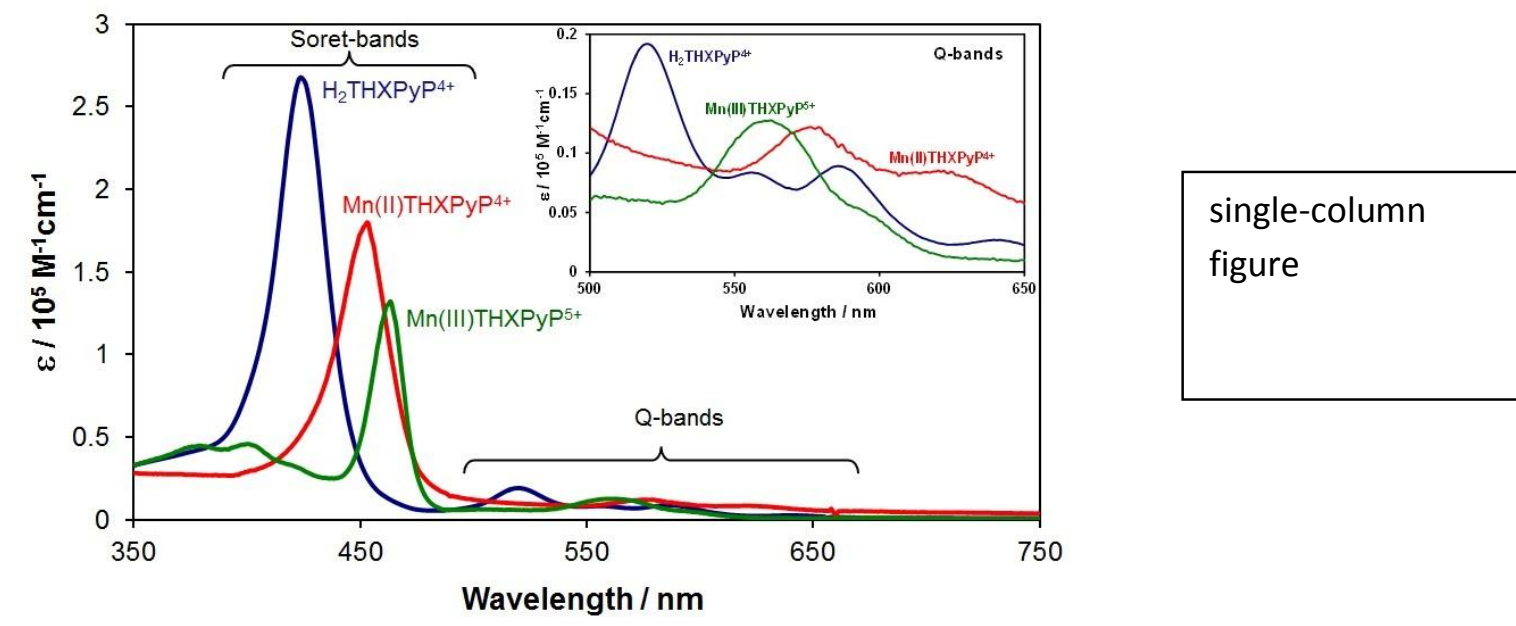

Fig 1. Molar absorption spectra of $\mathrm{Mn}(\mathrm{III})$ and $\mathrm{Mn}(\mathrm{II})$ complexes formed with $\mathrm{H}_{2} \mathrm{THXPyP}^{4+}$, compared to that of the free base.

Table 1. Characteristic absorption data of the Soret-band and some (stronger) Q-bands of cationic porphyrins of $\mathrm{Mn}(\mathrm{III})$ and $\mathrm{Mn}$ (II) as well as the corresponding free bases.

\begin{tabular}{|c|c|c|c|}
\hline \multirow[t]{2}{*}{ Species } & \multicolumn{2}{|c|}{ Wavelength/nm } & \multirow[t]{2}{*}{ Ref. } \\
\hline & Soret-band $(\lg \varepsilon)$ & Q-bands & \\
\hline $\mathrm{H}_{2} \mathrm{TMPyP}^{4+}$ & $422(5.35)$ & $521,558,585,642$ & {$[30$, this work] } \\
\hline $\mathrm{Mn}(\mathrm{III}) \mathrm{TMPy} \mathrm{P}^{5+}$ & $463(5.20)$ & 565,594 & {$[14$, this work] } \\
\hline Mn(II)TMPyP ${ }^{4+}$ & $445(5.28)$ & 575,625 & [14] \\
\hline
\end{tabular}




$\begin{array}{llll}\mathrm{H}_{2} \mathrm{THXPyP}^{4+} & 426(5.42) & 519,557,587,642 & {[15, \text { this work] }} \\ \text { Mn(III)THXPyP } & 463(5.12) & 562,596 & \text { [this work] } \\ \text { Mn(II)THXPyP } & 452(5.25) & 576,623 & \text { [this work] } \\ \mathrm{H}_{2} \text { TDPyP }^{4+} & 428(5.18)^{\mathrm{a}} & 519,555,592,648 & {[15, \text { this work] }} \\ \text { Mn(III)TDPyP }^{5+} & 463(5.15)^{\mathrm{a}} & 568,600 & \text { [this work] } \\ \text { Mn(II)TDPyP } & 456^{\mathrm{a}}\left(^{\mathrm{b}}\right) & \mathrm{b} & \text { [this work] }\end{array}$

a In 1:1 ethanol:water mixture, ${ }^{b}$ could not be determined due to the fast degradation of the ligand

The Soret-band of the manganese(II) porphyrins is also red-shifted compared to that of the related free base, however, it is blue-shifted in the relation of the corresponding (more distorted) manganese(III) hyper porphyrin. This phenomenon can be accounted for the larger $\mathrm{Mn}^{2+}$ ion $\left(r_{\text {ion }}=83 \mathrm{pm}\right)$, the metalloporphyrins of which are border-line cases displaying outof-plane characteristics, similarly to the iron(II) complex studied earlier [25, 31].

The absorption spectra of the Mn(III) complexes with the methyl, hexyl and dodecyl substituted pyridinium porphyrins do not show significant differences, indicating that the electronic interaction and structural (ruffle) distortion determining the band energy are not appreciably affected by the length of the alkyl group. However, the Soret bands of the freebase porphyrins display a slight red-shift if the length of this hydrocarbon chain grows. Even stronger red-shift can be observed in the case of the Mn(II) complexes between the methyl and hexyl substituted derivatives, suggesting that the distortion playing role in the out-ofplane characteristics is much more sensitive to the length of this alkyl group than in the hyper porphyrins. The size of this alkyl chain may considerably influence the rotation of the pyridinium group relative to the porphyrin plane. Apparently the qualitative difference between the hexyl and dodecyl groups in this respect is less significant.

\subsubsection{Emission properties}

The fluorescence bands in the 600-800-nm range of the emission spectra of porphyrins, both free bases and metalloporphyrins, can be assigned as $S_{1} \rightarrow S_{0}$ transitions; the individual bands correspond to the $(0,0),(0,1)$ and $(0,2)$ transitions with respect to vibrational states [25]. The fluorescence bands of metalloporphyrins (of any type) are blue-shifted and significantly less intense compared to those of the corresponding free-base porphyrin. The hypsochromic effect in the fluorescence is apparently in contrast with the red shift in the absorption. However, this blue shift-red shift anomaly is virtual, because in the case of free bases the emission derives not from the hypothetical average level, but from the energetically lower $S_{1 x}$-state (populated in $\mathrm{Q}_{\mathrm{x}}(0,0)$ absorption). 

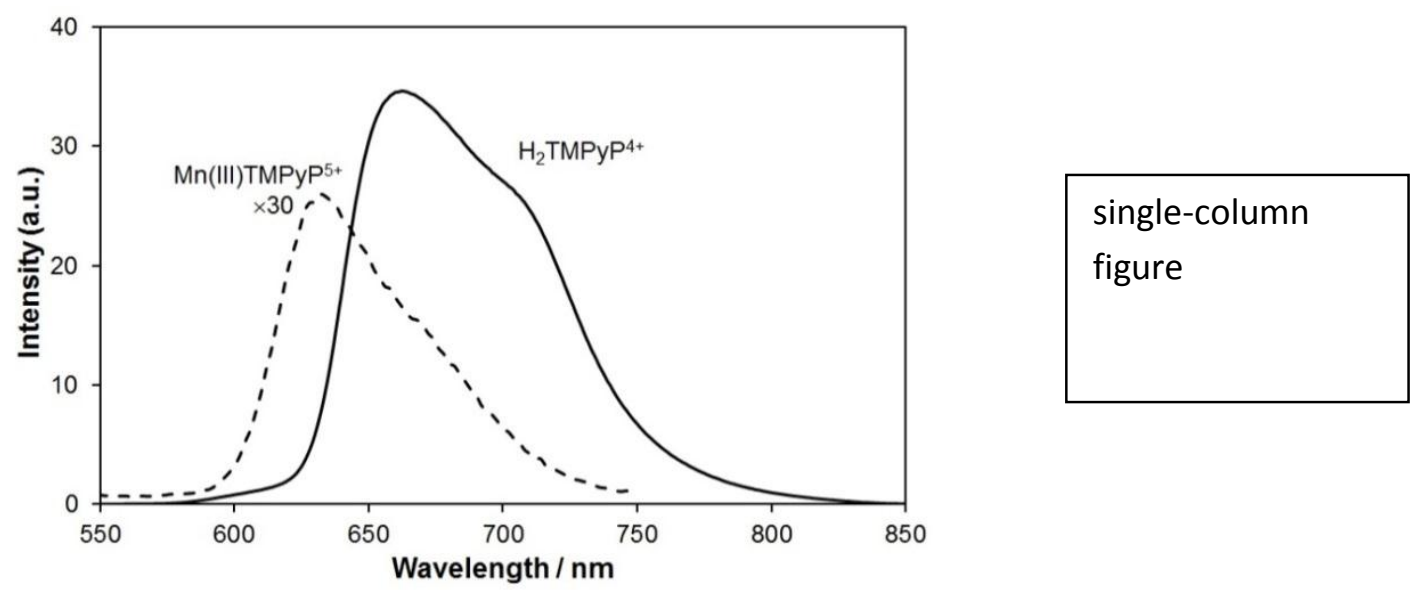

Fig 2. Emission spectra of $\mathrm{Mn}(\mathrm{III}) \mathrm{TMPyP}^{5+}$ and $\mathrm{H}_{2} \mathrm{TMPyP}^{4+}$ obtained by excitation at the Soret-bands in aqueous solution.

The fluorescence spectrum of Mn(III)TMPyP ${ }^{5+}$ obtained upon Soret-band excitation (Fig 2 and Table 1) is very similar to that of the manganese(III) complex with 5-[4-(5-carboxy-1butoxy)-phenyl-10,15,20-tris(1-methylpyridinium-4-yl)porphyrin [6], indicating the negligible effect of the deviating substituent of the latter porphyrin. In accordance with the expectations, the fluorescence peak of the previous complex is appreciably blue-shifted compared to the emission bands of the free base. However, even this blue shift is significantly smaller than the red shifts of the corresponding absorption bands (Table 1), suggesting that the structural difference between the ground $\left(\mathrm{S}_{0}\right)$ and the excited $\left(\mathrm{S}_{1}\right)$ states is bigger for the free base than for the metalloporphyrin. This phenomenon may be attributed to the predistortion (shrinking) effect of the metal center in the $S_{0}$ state, which decreases the structural change (distortion) upon excitation to the $\mathrm{S}_{1}$ state.

Fig 3. Emission spectra of $\mathrm{Mn}(\mathrm{III}) \mathrm{THXPyP}{ }^{5+}$ and $\mathrm{H}_{2} \mathrm{THXPyP}^{4+}$ obtained by excitation at the

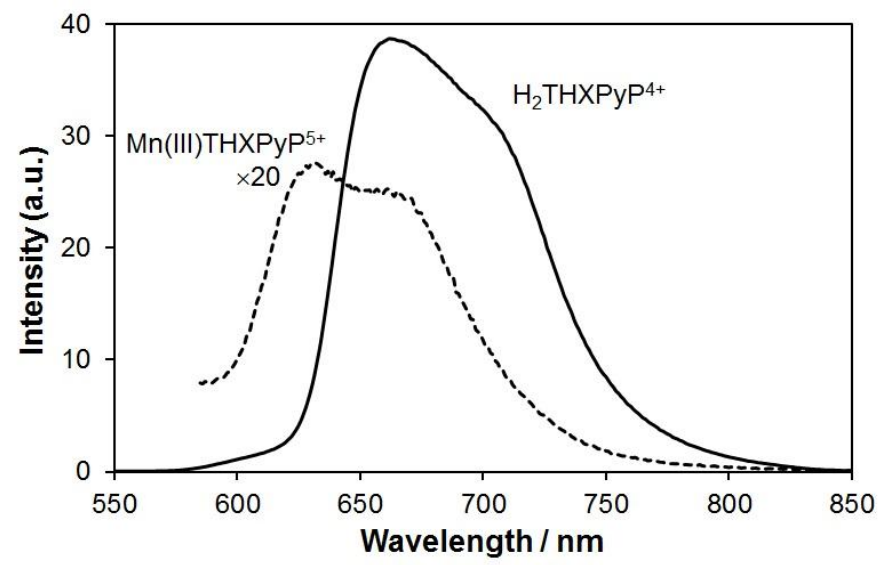

single-column

figure

Soret-bands in aqueous solution. 
Similarly to the absorption spectra, the fluorescence spectrum of $\mathrm{H}_{2} \mathrm{THXPyP}^{4+}$ (Fig 3, Table 2) did not show any significant deviation from that of $\mathrm{H}_{2} \mathrm{TMPyP}^{4+}$. However, in the case of the corresponding manganese(III) complexes, the intensity of the longer-wavelength $\mathrm{Q}(1,0)$ band of $\mathrm{Mn}(\mathrm{III}) \mathrm{THXPyP}{ }^{5+}$ (at $665 \mathrm{~nm}$ ) is comparable with that of the shorterwavelength $\mathrm{Q}(0,0)$ band (at $631 \mathrm{~nm}$ ), while for the methyl derivative the previous one is hardly perceptible (at ca. $668 \mathrm{~nm}$ ), only the asymmetry of the merged peak intimates its hidden existence. This phenomenon indicates that the longer alkyl substituent more efficiently promotes the transition to the vibrationally excited ground electronic state due to the higher inertia of the structure. In the case of the dodecyl derivatives, the emission bands of the free base are slightly blue-shifted compared to those of the methyl and hexyl derivatives (Fig 4, Table 2). Besides, the separation of the bands in the emission spectrum of $\mathrm{H}_{2} \mathrm{TDPyP}^{4+}$ is much stronger than in the previous cases, due to the solvent effect of ethanol (present for solubility reason).

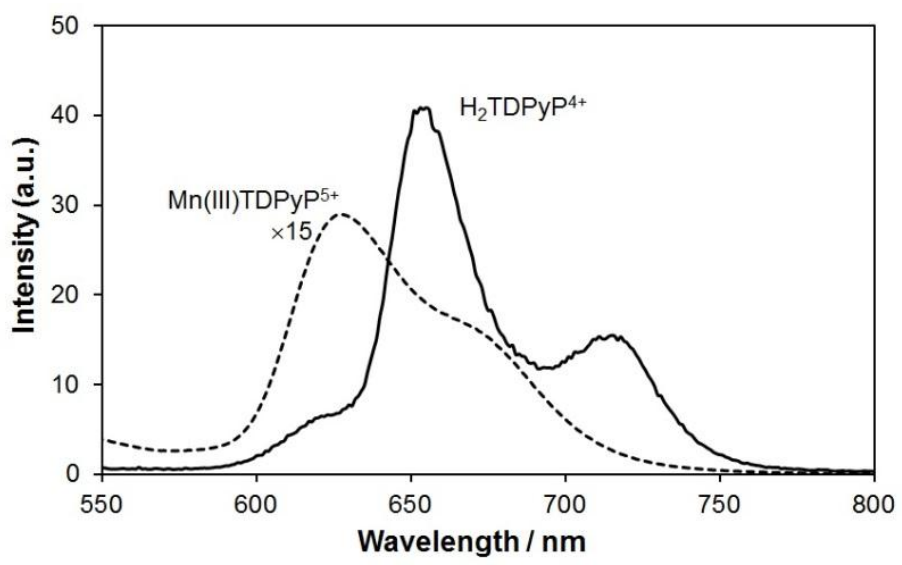

single-column

figure

Fig 4. Emission spectra of $\mathrm{Mn}(\mathrm{III}) \mathrm{TDPyP}^{5+}$ and $\mathrm{H}_{2} \mathrm{TDPyP}^{4+}$ obtained by excitation at the Soretbands in 1:1 ethanol:water mixture.

As shown in Figs 2-4, the intensity of the emission of the manganese(III) porphyrins is significantly (1-2 orders of magnitude) lower than that of the corresponding free bases. The radiation quantum yields measured at Soret-band excitation are in accordance with this observation as shown by the data in Table 2 . While the quantum yields $\left(\Phi_{\mathrm{r}}\right)$ for the manganese(III) porphyrins are in the order of $10^{-4}-10^{-3}$, those for the corresponding free bases are 1-2 orders of magnitude higher. Although the latter data were determined in methanol, their order of magnitude is the same as of those measured in water. This is demonstrated by the fluorescence quantum yields determined earlier for $\mathrm{H}_{2} \mathrm{TMPyP}^{4+}$ in aqueous solutions (0.030 [30], 0.040 [32]). The much weaker fluorescence of the manganese(III) complexes may be accounted for the in-plane position of the open-shell metal center as an electronic effect (strong interaction between the orbitals of the ligand and the metal), and the ruffled distortion as a steric effect. 
Table 2. Fluorescence bands $(\mathrm{Q}(0,0), \mathrm{Q}(1,0))$, quantum yields and lifetimes for the emission of cationic manganese(III) porphyrins and the corresponding free bases at Soret-band excitation in aqueous solution (unless otherwise stated).

\begin{tabular}{lccll}
\hline $\begin{array}{l}\text { free bases } \\
\text { and complexes }\end{array}$ & \multicolumn{2}{c}{$\begin{array}{c}\text { Q }(0,0) \\
\lambda / \mathrm{nm}\end{array}$} & $\begin{array}{c}\mathrm{Q}(1,0) \\
\Phi_{\mathrm{r}} \times 10^{5}\end{array}$ & lifetime / ns \\
\hline $\mathrm{H}_{2} \mathrm{TMPyP}^{4+}$ & 662 & 702 & $40\left(59^{\mathrm{a}}\right)$ & $9.8^{\mathrm{a}}$ \\
$\mathrm{H}_{2} \mathrm{THXPyP}^{4+}$ & 663 & 702 & $38\left(38^{\mathrm{a}}\right)$ & $9.2^{\mathrm{a}}$ \\
$\mathrm{H}_{2} \mathrm{TDPyP}^{4}+$ & 652 & 712 & $12^{\mathrm{b}}\left(27^{\mathrm{a}}\right)$ & $8.7^{\mathrm{a}}$ \\
& & & & \\
Mn(III)TMPyP & 632 & $\approx 668$ & 0.11 & 3.9 \\
Mn(III)THXPyP & 631 & 665 & 1.4 & 4.6 \\
Mn(III)TDPyP & 628 & 671 & $1.4^{\mathrm{b}}$ & $6.6^{\mathrm{b}}$ \\
\hline
\end{tabular}

${ }^{\mathrm{a}}$ In methanol [15].

${ }^{\mathrm{b}}$ In 1:1 ethanol:water mixture.

The quantum yields for the fluorescence of the free bases display a moderate, but monotonous decrease upon increasing the alkyl chain on the pyridinium substituent. This effect may be interpreted by an increased chance for energy loss from the excited state via non-radiative ways of decay (e.g. vibration). In the case of the manganese(III) porphyrins an opposite and more significant effect can be observed. The increase of the length of the alkyl chain (from methyl to hexyl) enhances the quantum yield by one order of magnitude. This considerable change may be explained by the stronger electron-donating effect of the hexyl group, increasing the basicity of the pyrrolic nitrogens as observed for the 5,10,15,20tetrakis(1-alkylpyridinium-2-yl)porphyrins (for the deprotonation of the free bases, $\mathrm{pK}_{\mathrm{a} 2}$ is 10.9 for the methyl and 12.2 for the hexyl derivatives [33]). This electronic effect increases the strength of the Mn-N coordinative bonds and, thus, the structural rigidity of $\mathrm{Mn}(\mathrm{III}) \mathrm{THXPyP}{ }^{5+}$, promoting the energy loss of the singlet excited state via light emission. In the case of the dodecyl derivative, however, no further increase of the quantum yield was observed, suggesting the leveling of this effect above a certain length of the alkyl chain.

Table 2 also indicates the fluorescence lifetimes for both the complexes and the corresponding free bases. The fluorescence decay of these species proved to be biexponential in each case; both in our experiments and in previous studies [15, 34]. Its longer component can be unambiguously assigned to the $S_{1} \rightarrow S_{0}$ transition, while the shorter one (with significantly lower amplitude) was interpreted in deviating ways (e.g. adsorption effect [34] or mixing of the $S_{1}$ and a CT state [15]). Hence, only the longer ones were taken into consideration for comparison (Table 2). Although the data regarding the free bases in Table 2 were determined in methanol, they are comparable with those measured in water as indicated by the values for $\mathrm{H}_{2} \mathrm{TMPyP}^{4+}$ : $6 \mathrm{~ns}$ [32], 5.2 [30].

The tendencies regarding the changes of lifetimes upon increasing the length of the alkyl chain are in accordance with those observed for the quantum yields. They show a monotonous, even if relatively slight decrease in the case of the free bases, while a more significant increase is indicated for the complexes. Notably, the latter tendency may be enhanced by the presence of ethanol in the case of the dodecyl derivative.

Since the photochemistry of the complexes were studied in cationic micellar systems too (see later), it was reasonable to measure the effect of such a microenvironment on their fluorescence lifetimes. For this purpose, these experiments were carried out in aqueous solutions containing $4.38 \times 10^{-3} \mathrm{M} \mathrm{CTAB}$, which means about $5.6 \times 10^{-5} \mathrm{M}$ concentration of the micelles, due to the aggregation number $(61)$ and the $\mathrm{CMC}\left(9.6 \times 10^{-5} \mathrm{M}\right)$ of this surfactant 
[35]. Hence the complex/micelle ratio was less than one. The fluorescence decay obeyed biexponential kinetics in this case too, and for comparison with the data obtained in homogeneous systems the lifetimes belonging to the major, longer lived components were taken. In contrast with the tendency observed in water, in micellar system the fluorescence lifetime decreased upon increasing the length of the alkyl chain (3.40 ns, $3.03 \mathrm{~ns}$, and $2.30 \mathrm{~ns}$ for Mn(III)TMPyP ${ }^{5+}, \mathrm{Mn}(\mathrm{III}) \mathrm{THXPyP}{ }^{5+}$, and Mn(III)TDPyP ${ }^{5+}$, respectively). This phenomenon, which is just the opposite of the change observed in the homogeneous aqueous system, can be interpreted by the stronger and stronger hydrophobic interaction between the alkyl chains of the surfactant in the micelles and those of the substituents on the porphyrins (in the order of methyl, hexyl, and dodecyl). This interaction can cause a moderate quenching of the fluorescence due to the energy loss via other, non-radiative ways. Since bromide ions originated from $\mathrm{CTAB}$ may also quench the fluorescence of these metalloporphyrins, the effect of $\mathrm{Br}^{-}$was checked in homogeneous aqueous solutions with addition of $\mathrm{KBr}$ up to $1 \times 10^{-2} \mathrm{M}$. No detectable quenching effect was observed in this concentration range of bromide ions, confirming the possible role of the hydrophobic interaction.

\subsection{Photochemistry}

Although Mn(III)TMPyP ${ }^{5+}$ was studied much earlier in a photoredox catalytic cycle in the presence of TEOA and $\mathrm{MV}^{2+}$ as electron donor and acceptor, respectively [14], its reproduction was necessary for comparison. Beside the methyl derivative, $\mathrm{Mn}(\mathrm{III}) \mathrm{THXPyP} \mathrm{P}^{5+}$ was also studied under the same conditions. As Fig 5 indicates, similarly to Mn(III)TMPyP ${ }^{5+}$, at the applied concentrations, photocatalytic generation of $\mathrm{MV}^{\bullet+}$ could be achieved with this photocatalyst, too. A blind probe was also carried out; no spectral change occurred in the dark (i.e., without irradiation) indicating that without photoexcitation no redox reactions take place in this system.

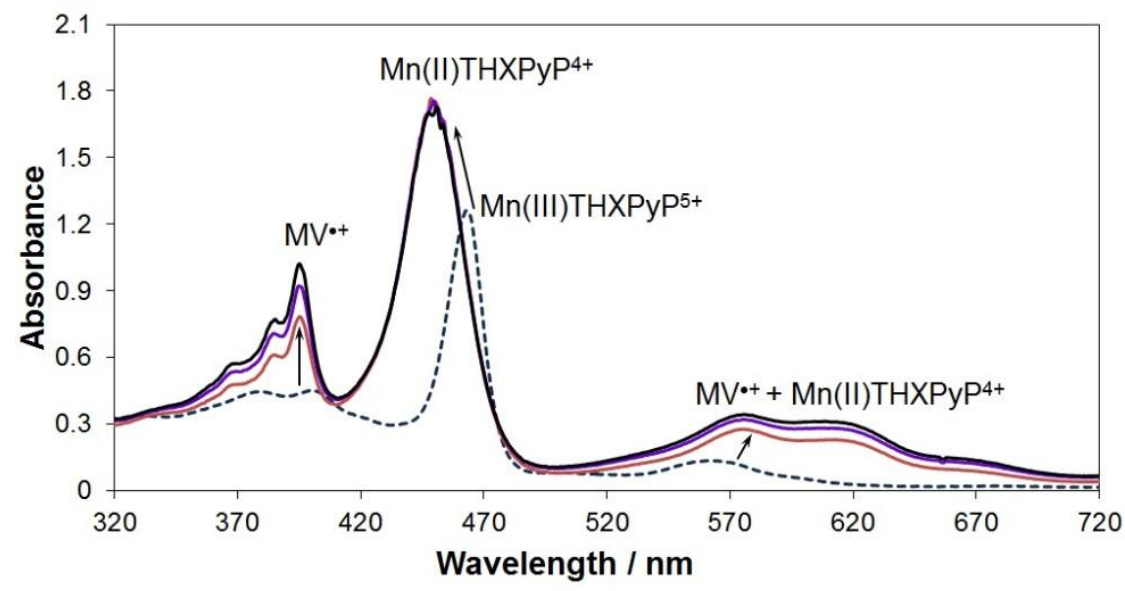

single-column

figure

Fig 5. Spectral change in the system initially containing $1 \times 10^{-5} \mathrm{M} \mathrm{Mn}(\mathrm{III}) \mathrm{THXPyP} \mathrm{P}^{5+}, 5 \times 10^{-4}$ $\mathrm{M}$ TEOA and $2 \times 10^{-3} \mathrm{M} \mathrm{MV}^{2+}$ during the irradiation at $0,10,20$, and $30 \mathrm{~min}\left(\lambda_{\text {ir }}=463 \mathrm{~nm}, \boldsymbol{\ell}\right.$ $=1 \mathrm{~cm})$.

In the first step of the catalytic cycle photoinduced reduction of the manganese(III) complex with TEOA (Eq 1) took place as shown by the change in the position (from 463 to $452 \mathrm{~nm}$ ) and intensity of the Soret band. In the next redox reaction (Eq 2) the corresponding manganese(II) porphyrin $\left(\mathrm{Mn}(\mathrm{II}) \mathrm{TMPyP}^{4+}\right.$ in this case) photochemically reduced $\mathrm{MV}^{2+}$ to $\mathrm{MV}^{\bullet+}$ as indicated by the appearance of the characteristic band of the latter species at $398 \mathrm{~nm}$ [36]. 
$\mathrm{Mn}(\mathrm{III}) \mathrm{THXPyP}{ }^{5+}+\mathrm{TEOA}+\mathrm{h} v \rightarrow \mathrm{Mn}(\mathrm{II}) \mathrm{THXPyP}^{4+}+\mathrm{TEOA}_{\mathrm{ox}}$

$\mathrm{Mn}(\mathrm{II}) \mathrm{THXPyP}^{4+}+\mathrm{MV}^{2+}+\mathrm{h} v \rightarrow \mathrm{Mn}(\mathrm{III}) \mathrm{THXPyP}^{5+}+\mathrm{MV}^{\bullet+}$

The other characteristic, but much wider and less intensive weaker band of $\mathrm{MV}^{\bullet+}$ at $605 \mathrm{~nm}$ merged with the 576- and 623-nm Q-bands of Mn(II)THXPyP ${ }^{4+}$ (Fig 5).

As shown in Fig 5, in accordance with the previous observations [1,14], practically the whole amount of the starting manganese(III) complex was converted to the corresponding $\mathrm{Mn}(\mathrm{II})$ species in the initial period of irradiation. The +2 oxidation state of the metal center persisted till the end of the 210-min illumination. This phenomenon indicates that the rate of the reduction of $\mathrm{Mn}(\mathrm{III})$ porphyrin is higher than that of the oxidation of the $\mathrm{Mn}$ (II) species in this period of time. After depletion of most of TEOA, the oxidation state of the metal center gradually returns to +3 . However, in the case of the hexyl derivative, during this irradiation period more than 55\% degradation of the porphyrin ligand took place. The methyl derivative proved to be more stable; less than $22 \%$ decomposition was observed during the same illumination time. Notably, the dodecyl derivative $\left(\mathrm{Mn}(\mathrm{III}) \mathrm{TDPyP}^{5+}\right.$ ) could not function as an efficient photocatalyst in such a system because of the fast degradation of the porphyrin ligand. These results clearly indicate that elongation of the alkyl substituent on these manganese(III) porphyrins significantly decreases the stability of these complexes against photoredox degradation. It may be the consequence of the increased electron-donating character of the substituent, which can promote a photoinduced ligand-to-metal charge transfer (LMCT), leading to an irreversible cleavage of the porphyrin ring. This is a typical photochemical reaction of the out-of-plane (OOP) or sitting-atop (SAT) metalloporphyrins, in which the metal center, due to its relatively big size compared to the coordination cavity, is located out of the ligand plane $[1,22,24,31]$. Since the $\mathrm{Mn}^{2+}$ center formed in the first

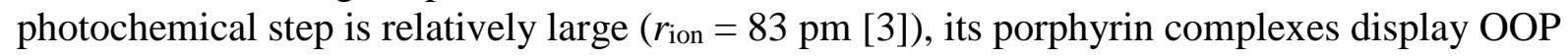
characteristics [25].

In an independent experiment it was confirmed that manganese(II) porphyrins in ground state cannot react with $\mathrm{MV}^{2+}$. This electron acceptor was added to the system (in the dark, under anaerobic conditions) only after the photoreductive generation of the manganese(II) species. No formation of $\mathrm{MV}^{\bullet+}$ was observed, in accordance with the ground-state redox potentials [14]. Therefore, excitation of the reduced catalyst (e.g., $\mathrm{Mn}(\mathrm{II}) \mathrm{THXPyP}{ }^{4+}$ ) is indispensable for the electron transfer toward the methylviologen as indicated in Eq. 2. The overall quantum yield $(\Phi)$ for the formation of $\mathrm{MV}^{\bullet+}$ in these photocatalytic systems was determined from the initial rate of the accumulation of this radical. An increase of the alkyl substituent from methyl to hexyl enhanced $\Phi$ from 1.5 to $2.5 \%$. The order of magnitude of these values agrees with that obtained for Co(III)TMPyP ${ }^{5+}$ under similar conditions [5], and may be considerable for a potential application of such a system for hydrogen generation from water, combined with a suitable co-catalyst such as colloidal palladium or platinum [37].

Beside the change of the alkyl substituent, the effects of micellar environment on these photocatalytic processes were also investigated. In the presence of $1.2 \times 10^{-2} \mathrm{M}$ sodium lauryl sulfate (SLS) no reduction of the $\mathrm{Mn}^{3+}$ metal center was detected in the case of $\mathrm{Mn}(\mathrm{III}) \mathrm{TMPyP}^{5+}$. This phenomenon may be attributed to the strong attraction between the oppositely charged micelles and metalloporphyrins, sterically (and perhaps also electronically) hindering the electron transfer from TEOA. Interestingly, Mn(III)THXPyP ${ }^{5+}$, under the same conditions, underwent the photoinduced reduction, but no generation of $\mathrm{MV}^{\bullet+}$ took place in this system. Accordingly, the longer alkyl chain promoted the reduction of the metal center, in agreement with the enhanced overall quantum yield in homogeneous aqueous solution. The lack of the $\mathrm{MV}^{\bullet+}$ accumulation can also be accounted for the strong coulomb interaction between the negatively charged micellar surface and $\mathrm{MV}^{2+}$, hindering the redox 
reaction of the latter species. Cationic micelles, in the solutions containing $4.4 \times 10^{-3} \mathrm{M}$ cetyltrimethylammonium bromide (CTAB), significantly enhance the quantum yields by about $40 \%$ for both manganese(III) porphyrins studied. Besides, the maximum steady-state concentration of $\mathrm{MV}^{\bullet+}$ increased too in a similar order of magnitude, due to the promotion of charge separation and the hindrance of the back reactions between the products of the redox processes. Additionally, a moderate increase of the stability of the Mn(III)TMPyP ${ }^{5+}$ photocatalyst was also observed in the presence of cationic micelles; its degradation decreased (from ca. 22\%) to 15\% during the 210-min irradiation. The durability of the hexyl derivative, however, was not appreciably influenced by the cationic microenvironment, indicating the determining role of the longer alkyl substituent in this respect.

Although the photochemistry of cationic manganese(III) porphyrins was investigated earlier in photoredox catalytic cycles in the presence of TEOA and $\mathrm{MV}^{2+}[1,14]$, the role of the excited states was not elucidated in those systems. Hence, Mn(III)TMPyP ${ }^{5+}$, as the simplest representative of the complexes in this work, has been chosen for this purpose. Since the singlet excited state of this metalloporphyrin is too short-lived (3.9 ns) to be efficiently quenched by TEOA, one can expect its triplet to play role in the first redox step (Eq 1). In order to confirm this assumption, flash photolysis experiments were carried out with this complex. A long-lived ( $\left.\tau_{0}=53 \mu \mathrm{s}\right)$ transient was detected upon excitation at $540 \mathrm{~nm}$ (Fig. 6), which can be assigned to the triplet state of Mn(III)TMPyP ${ }^{5+}$. As the Stern-Volmer plot indicates (Fig 6 inset), this triplet state could be efficiently quenched with TEOA $\left(\mathrm{k}_{\mathrm{q}}=\right.$ $\left.6.7 \times 10^{6} \mathrm{M}^{-1} \mathrm{~s}^{-1}\right)$, confirming our suggestion. This value is similar to that obtained for Co(III) $\mathrm{TMPyP}^{5+}$ under the same conditions [5]. Since the formation of methylviologen radical needs excitation of the manganese(II) porphyrin formed in the reductive quenching with TEOA, an oxidative quenching of the triplet $\mathrm{Mn}$ (II)TMPyP ${ }^{4+}$ with $\mathrm{MV}^{2+}$ is reasonable in the secondary redox step in this photocatalytic system.

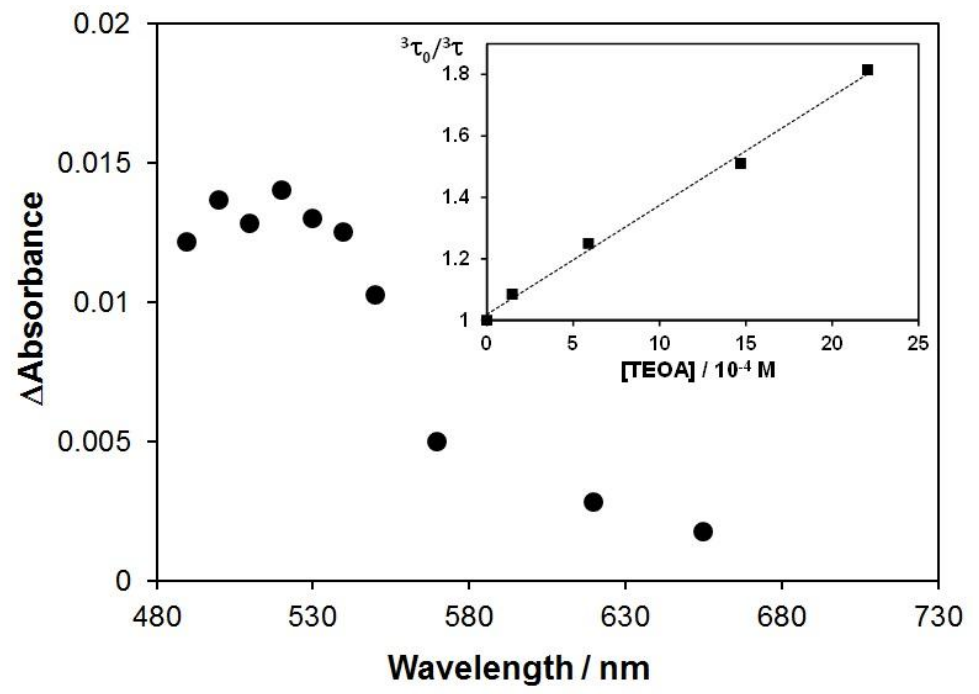

single-column

figure

Fig 6. Transient absorption spectrum right after a 540-nm laser pulse in aqueous solution containing $1 \times 10^{-5} \mathrm{M} \mathrm{Mn}(\mathrm{III}) \mathrm{TMPyP}^{5+}$. Inset: Stern-Volmer plot of its quenching by triethanolamine (TEOA). 


\section{Conclusions}

As typical representatives of in-plane hyper porphyrins, cationic manganese(III) complexes were studied from photophysical and-chemical points of view. The effects of changing the length of the alkyl group on the pyridinium substituents were investigated in homogeneous solutions and micellar systems. Deviating from the tendency observed for the fluorescence of the free ligands, elongation of the alkyl chain enhanced the emission efficiency and lifetime of the metalloporphyrins. Cationic micelles inverted the latter trend, due to hydrophobic interactions. Similarly to the behavior of Co(III)TMPyP ${ }^{5+}$, in the photocatalytic system containing TEOA and $\mathrm{MV}^{2+}$ as electron donor and acceptor, respectively, reductive quenching of the triplet excited state of the cationic manganese(III) porphyrins led to the formation of the corresponding, thermodynamically stable $\mathrm{Mn}$ (II) complexes. Photoinduced electron transfer from these species toward $\mathrm{MV}^{2+}$ generated $\mathrm{MV}^{\bullet+}$, which, using an appropriate co-catalyst, can generate hydrogen from water. Elongation of the alkyl substituent resulted in contradictory effects on this photocatalytic system. The influence of the micellar environment dramatically depended on the charge of the surfactant applied, due to predominantly electrostatic interactions. These results well demonstrated how significantly the water-solubilizing substituents and the micellar environment affect the photoinduced behavior of these cationic manganese(III) porphyrins.

\section{Acknowledgment}

This work was supported by the Hungarian Scientific Research Fund (OTKA K101141 and NN107310) and the Austrian-Hungarian Action Foundation (90öu2).

\section{References}

1. O. Horváth, Z. Valicsek, G. Harrach, G. Lendvay, M.A. Fodor, Spectroscopic and photochemical properties of water-soluble metalloporphyrins of distorted structure, Coord. Chem. Rev. 256 (2012) 1531-1545.

2. K. T. Oppelt, E. Wöß, M. Stiftinger, W. Schöfberger, W. Buchberger, G. Knör, Photocatalytic Reduction of Artificial and Natural Nucleotide Co-factors with a ChlorophyllLike Tin-Dihydroporphyrin Sensitizer, Inorg. Chem. 52 (2013) 11910-11922.

3. R.D. Shannon, Revised Effective Ionic Radii and Systematic Studies of Interatomic Distances in Halides and Chaleogenides, Acta Crystallogr., Sect. A: Found. Crystallogr. 32 (1976) 751-767.

4. K. Kalyanasundaram, M. Neumann-Spallart, Photophysical and redox properties of watersoluble porphyrins in aqueous media, J. Phys. Chem. 86 (1982) 5163-5169.

5. M. A. Fodor, O. Horváth*, L. Fodor, G. Grampp, A. Wankmüller, Photophysical and photocatalytic behavior of cobalt(III) 5,10,15,20-tetrakis(1-methylpyridinium-4-yl)porphyrin, Inorg. Chem. Commun. 50 (2014) 110-112.

6. M. Makarska-Białokoz, G. Pratviel, St. Radzki, The influence of solvent polarity on spectroscopic properties of 5-[4-(5-carboxy-1-butoxy)-phenyl]-10,15,20-tris (4-Nmethylpyridiniumyl)porphyrin and its complexes with Fe(III) and Mn(III) ions, J. Mol. Struct. 875 (2008) 468-477. 
7. E. Fagadar-Cosma, M. C. Mirica, I. Balcu, C. Bucovicean, C. Cretu, I. Armeanu, G. Fagadar-Cosma, Syntheses, spectroscopic and AFM characterization of some manganese porphyrins and their hybrid silica nanomaterials, Molecules 14 (2009) 1370-1388.

8. S.-M. Chen, The photocatalytic autoxidation of sulfur oxoanions by water-soluble porphyrin complexes, J. Mol. Catal. A 138 (1999) 1-13.

9. I. Kikaš, O. Horváth, I. Škorić, Functionalization of the benzobicyclo[3.2.1]octadiene skeleton via photocatalytic and thermal oxygenation of a furan derivative, Tetrahedron Lett. 52 (2011) 6255-6259.

10. I. Kikaš, O. Horváth, I. Škorić, Functionalization of the benzobicyclo[3.2.1]octadiene skeleton via photocatalytic oxygenation of furan and benzofuran derivatives, J. Mol. Struct. 1034 (2013) 62-68.

11. D. Vuk, I. Kikaš, K. Molčanov, O. Horváth, I. Škorić, Functionalization of the benzobicyclo[3.2.1] octadiene skeleton via photocatalytic oxygenation of thiophene and furan derivatives: the impact of the type and position of the heteroatom, J. Mol. Struct. 1063 (2014) 83-91.

12. Y. H. Kim, S. D. Jung, M. H. Lee, C. Im, Y-H. Kim, Y. J. Jang, S. K. Kim, D. W. Cho, Photoinduced reduction of manganese(III) meso-tetrakis(1-methylpyridinium- 4-yl)porphyrin at AT and GC base pairs, J. Phys. Chem. B 117 (2013) 9585-9590.

13. A. Harriman, G. Porter, Photochemistry of Manganese Porphyrins Part $2-$ Photoreduction, J. Chem. Soc. Faraday Trans. II. 75 (1979) 1543-1552.

14. K. Takahashi, T. Komura, H. Imanaga, Light-induced redox characteristics of [tetrakis(4methylpyridyl)porphyrinato]manganese(III), Bull. Chem. Soc. Jpn. 56 (1983) 3203-3207.

15. X. He, Y. Zhou, L. Wang, T. Li, M. Zhang, T. Shen, Photophysical properties of amphiphilic porphyrins in different media, Dyes Pigments 39 (1998) 173-182.

16. M. Tabata, W. Miyata, N. Nahar, Kinetics and mechanism of metal-substitution reaction of homodinuclear mercury(II) porphyrin with zinc(II) with particular reference to a heterodinuclear metalloporphyrin intermediate, Inorg. Chem. 34 (1995) 6492-6496.

17. J.Y. Tung, J.-H. Chen, Crystal and molecular structure of an eight-coordinate Nmethyltetraphenylporphyrin complex: diacetato(N-methyl-meso-

tetraphenylporphyrinato)thallium(III), Inorg. Chem. 39 (2000) 2120-2124.

18. J. Van Houten, R. J. Watts, Temperature-dependence of photophysical and photochemical properties of tris(2,2-bipyridyl)ruthenium(II) ion in aqueous solution, J. Am. Chem. Soc. 98 (1976) 4853-4858.

19. G. Angulo, G. Grampp, A. A. Neufeld, A. I. Burshtein, Delayed fluorescence due to annihilation of triplets produced in recombination of photo-generated ions J. Phys. Chem. A 107 (2003) 6913-6919.

20. J. F. Rabek, Experimental methods in photochemistry and photophysics; WileyInterscience; New York, 1982.

21. A.D. Kirk, C. Namasivayam, Errors in ferrioxalate actinometry, Anal. Chem. 55 (1983) 2428-2429. 
22. O. Horváth, R. Huszánk, Z. Valicsek, G. Lendvay, Photophysics and photochemistry of kinetically labile, water-soluble porphyrin complexes, Coord. Chem. Rev. 250 (2006) 17921803.

23. O. Horváth, Z. Valicsek, A. Vogler, Unique photoreactivity of mercury(II) 5,10,15,20tetrakis(4-sulfonatophenyl)porphyrin, Inorg. Chem. Commun. 7 (2004) 854.

24. Z. Valicsek, G. Lendvay, O. Horváth, Equilibrium, photophysical, photochemical and quantum chemical examination of anionic mercury(II) mono- and bisporphyrins, J. Phys. Chem. B 112 (2008) 14509-14524.

25. Z. Valicsek, O. Horváth, Application of the electronic spectra of porphyrins for analytical purposes: The effects of metal ions and structural distortions, Microchem. J. 107 (2013) 4762.

26. M. Gouterman, in D. Dolphin (Ed.), The Porphyrins, Optical Spectra and Electronic Structure of Porphyrins and Related Rings, vol. 3, Academic Press, New York, 1978, pp. 1165.

27. K. S. Suslick, R. A. Watson, The photochemistry of chromium, manganese, and iron porphyrin complexes, New J. Chem. 16(1992) 633-642.

28. H. Kobayashi, Y. Yanagawa, H. Osada, S. Minami, M. Shimizu, Electronic spectrra of high-spin iron(III) tetraphenylporphins, Bull. Chem. Soc. Jpn. 46 (1973) 1471-1479.

29. M. Gouterman, L. K. Hanson, G.-E. Khalil, W. R. Leenstra, J. W. Buchler, Porphyrins. XXXII. Absorptions and luminescence of Cr(III) complexes, J. Chem. Phys. 62 (1975) 23432353.

30. Z. Valicsek, O. Horváth, K. Patonay, Formation, photophysical and photochemical properties of water-soluble bismuth(III) porphyrins: the role of the charge and structure, J. Photoch. Photobio. A 226 (2011) 23-35.

31. R. Huszánk, G. Lendvay, O. Horváth, Air stable, heme-like water-soluble iron(II) porphyrin: in-situ preparation and characterization, J. Bioinorg. Chem. 12 (2007) 681-690.

32. K. Kalyanasundaram, Photochemistry of water-soluble porphyrins: comparative study of isomeric tetrapyridyl- and tetrakis( N-methylpyridiniumy1)porphyrins, Inorg. Chem. 23 (1984) 2453-2459.

33. I. Fridovich, I. Batinic-Haberle, Substituted Porphyrins, Patent US20020042407 A1, 2002.

34. F. J. Vergeldt, R. B. M. Koehorst, A. van Hoek, T. J. Schaafsma, Intramolecular interactions in the ground and excited state of tetrakis(N-methylpyridy1)porphyrins, J. Phys. Chem. 99 (1995) 4397-4405.

35. T. J. V. Prazeres, M. Beija, F. V. Fernandes, P. G. A. Marcelino, J. P. S. Farinha', J. M. G. Martinho, Determination of the critical micelle concentration of surfactants and amphiphilic block copolymers using coumarin 153, Inorg. Chim. Acta 381 (2012) 181-187. 
36. T. Watanabe, K. Honda, Measurement of the extinction coefficient of the methyl viologen cation radical and the efficiency of its formation by semiconductor photocatalysis, J. Phys. Chem. 86 (1982) 2617-2619.

37. C. G. Silva, M. de Miguel, B. Ferrer, M. Álvaro, H. García, Enhanced efficiency of the visible-light photocatalytic hydrogen generation by the ruthenium tris(2,2'-bipyridyl)methyl viologen system in the presence of cucurbit[n]urils, Photochem. Photobiol. Sci. 8 (2009) 1650-1654. 